LAPORAN KASUS

\title{
Penggunaan Opioid sebagai Balans Anestesi pada Craniotomi Emergensi dengan Meningioma
}

\section{Opioid In Balanced Anesthesia for Emergency Craniotomy with Meningioma}

Yutu Solihat*

*Bagian Anestesiologi dan Terapi Intensif Universitas Sumatera Utara/ RSU Haji Adam Malik Medan

\section{ABSTRACT}

Background: Balanced anesthesia is a technique of general anesthesia based on the concept that administration of mixture agent inhalation and intravenous or combinations anesthesia technique for desired advantages effect anesthesia. Opioid as one component of balanced anesthesia proven can reduce perioperative pain and anxiety, decrease somatic and autonomic responses to airway manipulation, improve hemodynamic stability during noxious stimulation due to surgery, lower requirements for inhaled anesthetics, and provide immediate postoperative analgesia. The goal of maintenance anesthesia in neurosurgery is controlling brain tension through control cerebral metabolic rate for oxygen consumption $\left(\mathrm{CMRO}_{2}\right)$ and cerebral blood flow $(C B F)$. The specific anesthetic regimen is a combination of drugs that favorably affects cerebral hemodynamics, $\mathrm{CMRO}_{2}$, and intracranial pressure (ICP) to provide good operating conditions and to enhance the probability of a quality outcome. Opioid generally produce modest decreases in the cerebral metabolic rate (CMR) and intracranial pressure although such changes are influenced by the concomitant administration of other agents and anesthetics.

Case: A female, 42 years old, predicted body weight $60 \mathrm{~kg}$ was admitted to the hospital with main complain decreased level of consciousness suddenly. (meningioma) on the parietal lobe.History of headache was found, no vomittus, and no seizure. Physical examination revealed sensorium Glasgow Coma Scale 10 (E3M5V2), status hemodynamic, we respiratory, laboratory and radiology findings were within normal limits. Patient was scheduled for craniotomy emergency tumor removal under general anesthesia intubation using endotracheal tube with opioid in balanced anesthesia using fentanil.

Operation lasted for 3 hours. Intravenous injection of midazolam (2 mg) as 
premedication was administered prior to anesthesia induction, fentanil 250 ug iv (titration) was given 5 minute before propofol injection to reach peak level before intubation. Induction with propofol $100 \mathrm{mg}$ iv (titration) and muscle relaxant with rocuronium $50 \mathrm{mg}$ iv was given. During anesthesia patient fully controlled, maintenanced $\mathrm{O}_{2}$ :air 2l:2l, sevoflurane 0,5-1\%, rocuronium $10 \mathrm{mg} / \mathrm{hours} / \mathrm{iv}$ and fentanil 100-200 ug/ hours/iv syringe pump. Totally fentanil used was 900 ug and at the end of surgery patient extubated. Pain management post operative used in ICU was fentanil 500 uq/24 hours/iv and ketorolac $30 \mathrm{mg} / 8$ hours/iv. Reassessed the level of consciousness post operative in ICU was GCS 15.

Discussions: It has been reported that opioid in balanced anesthesia with tumor removal (meningioma) in emergency craniotomy provide good operating conditions and excellent outcome. Opioid in balanced anesthesia is a good choice for this case. Plasma opioid concentrations required to blunt hemodynamic responses to laryngoscopy, tracheal intubation, and various noxius stimuli, as well as plasma opioid concentration associated with awakening from anesthesia and proven not increased cerebral metabolic and intracranial pressure. Opioid dosage is titrated to the desired effect based on surgical stimulus and revealed good recovery.

Keywords: Opioid in balanced anesthesia, neuroanesthesia, emergency craniotomy, meningioma.

\section{ABSTRAK}

Latar Belakang: Balans anestesi adalah teknik anestesi umum berdasar konsep pemberian campuran agen inhalasi dan intravena atau teknik anestesi kombinasi untuk mendapatkan keuntungan efek anestesi.

Opioid sebagai salah satu komponen balans anestesi terbukti dapat mengurangi nyeri perioperatif dan cemas, mengurangi respon somatik dan respon otonom terhadap manipulasi saluran napas, meningkatkan stabilitas hemodinamik selama rangsang nyeri operasi, kebutuhan anestesi inhalasi yang lebih rendah, dan memberikan analgesi segera pasca operasi. Tujuan maintenans anestesi pada bedah saraf adalah mengontrol tekanan otak melalui kontrol tingkat konsumsi oksigen metabolisme otak (CMRO2) dan aliran darah otak $(\mathrm{CBF})$. Preparat anestesi spesifik merupakan kombinasi obat yang menguntungkan hemodinamik serebral, $\mathrm{CMRO}_{2}$, dan tekanan intrakranial (ICP) untuk 
memberikan kondisi operasi yang baik dan untuk meningkatkan kemungkinan hasil yang berkualitas. Opioid umumnya menghasilkan penurunan sederhana dalam tingkat metabolisme otak (CMR) dan tekanan intrakranial meskipun perubahan tersebut dipengaruhi dengan pemberian agen lain.

Kasus: Seorang wanita, 42 tahun, berat badan $60 \mathrm{~kg}$ dirawat di rumah sakit dengan keluhan utama penurunan kesadaran tiba-tiba. CT scan menunjukkan tumor (meningioma) pada lobus parietal. Terdapat riwayat sakit kepala, tidak ada muntah, dan tidak kejang. Pemeriksaan fisik menunjukkan Glasgow Coma Scale 10 (E3M5V2), status hemodinamik, pernafasan, pemeriksaan laboratorium dan radiologi dalam batas normal. Pasien dijadwalkan untuk kraniotomi pengangkatan tumor emergensi di bawah anestesi umum, intubasi dengan endotrakeal tube dan opioid dalam balans anestesi menggunakan fentanil . Operasi berlangsung selama 3 jam. Injeksi intravena midazolam $2 \mathrm{mg}$ sebagai premedikasi diberikan sebelum induksi anestesi, fentanil 250 ug/iv (titrasi) diberikan 5 menit sebelum injeksi propofol untuk mencapai tingkat puncak sebelum intubasi. Induksi dengan propofol $100 \mathrm{mg}$ iv (titrasi) dan pelumpuh otot dengan rokuronium $50 \mathrm{mg} \mathrm{iv}$. Selama anestesi, pasien dikontrol secara total, maintenans O2:udara $2 l: 2 l$, sevofluran 0,5-1 \% , rocuronium $10 \mathrm{~m} / \mathrm{jam} / \mathrm{iv}$ dan fentanil 100-200 ug/jam/ iv syringe pump. Total fentanil digunakan adalah 900 ug dan pada akhir operasi pasien diekstubasi. Manajemen nyeri pasca operasi yang digunakan di ICU adalah fentanil 500 uq/24 jam/iv dan ketorolak 30mg/ 8 jam/iv. Pada asesmen ulang tingkat kesadaran pasca operasi di ICU didapatkan GCS 15.

Pembahasan: Opioid dalam balans anestesi pada pengangkatan tumor (meningioma) pada kraniotomi emergensi memberikan kondisi dan hasil operasi yang baik. Opioid dalam balans anestesi adalah pilihan yang baik untuk kasus ini. Konsentrasi plasma opioid yang diperlukan untuk menumpulkan respon hemodinamik terhadap laringoskopi, intubasi trakea, dan berbagai rangsangan noxius, serta konsentrasi plasma opioid yang terkait dengan kebangkitan dari anestesi dan terbukti tidak meningkatkan metabolisme otak dan tekanan intrakranial. Opioid dosis dititrasi untuk efek yang diinginkan berdasarkan stimulus bedah dan menghasilkan pemulihan yang baik. Kata kunci: Opioid dalam balans anestesi, neuroanesthesia, kraniotomi emergensi, meningioma . 


\section{PENDAHULUAN}

Terminologi balanced anesthesia pertama kali diperkenalkan oleh Jhon S. Lundy (Mayo Clinic) pada tahun 1926. Opioid menjadi pilihan dalam balanced anesthesia karena merupakan analgetik yang kuat (strong analgesia) sehingga mampu mengurangi nyeri perioperatif, mengurangi kecemasan (anxiety), mengurangi respon somatik dan autonom terhadap tindakan manipulasi airway, menghasilkan kestabilan hemodinamik yang dihubungkan dengan adanya stimulus noxious (tindakan pembedahan). ${ }^{1,2,3}$

Keuntungan opioid dalam balance anesthesia ialah menghasilkan analgesi segera pasca operasi yang baik, bersifat sinergistik sehingga dapat mengurangi kebutuhan propofol dan agen hipnotiksedatif yang lain selama rangsangan noksius seperti insisi kulit selama pembedahan, yang berujung dapat mengurangi biaya dengan tujuan akhir adalah mempercepat pemulihan pasien. $^{1,4}$

Tujuan dari manajemen anestesi untuk bedah syaraf adalah mengatur keseimbangan terhadap tekanan di kepala dengan cara mempertahankan $\mathrm{CMRO}_{2}$ dan CBF. Opioid secara umum dapat menurunkan kebutuhan metabolik rata-rata (CMR) dan tekanan intrakranial meskipun seiring dengan pemakaian agen anestesi yang lain. ${ }^{1,5}$

\section{KASUS}

Seorang pasien perempuan, 42 tahun, berat badan $60 \mathrm{~kg}$ datang dengan keluhan utama penurunan kesadaran mendadak sehari sebelum masuk rumah sakit. Hasil CT scan dijumpai meningioma di lobus parietal. Adanya riwayat sakit kepala, tidak dijumpai muntah maupun kejang sebelumnya dan dari pemeriksaan fisik dinilai tingkat kesadaran dengan GCS 10 (E3M5V2). Pemeriksaan fisik dan penunjang yang lain dalam batas normal. Pasien direncanakan untuk tindakan pembedahan emergensi pengangkatan tumor kepala secara kraniotomi dengan teknik anestesi umum menggunakan pipa endotrakeal. Premedikasi dengan 2 mg midazolam iv diberikan sebelum dilakukan induksi anestesi, fentanil 250 ug iv secara titrasi selama 5 menit sebelum injeksi propofol untuk mencapai kadar puncak dalam plasma. Induksi dengan propofol $100 \mathrm{~g}$ iv (titrasi) dan diberikan obat pelumpuh otot dengan rocuronium $50 \mathrm{mg}$ iv. Selama anestesi berlangsung pemeliharaan diberikan dengan $\mathrm{O}_{2}$ :air 21:21, agen inhalasi sevofluran 0,5-1\%, rocuronium $10 \mathrm{mg} / \mathrm{jam} / \mathrm{iv}$, dan fentanil 100-200 ug/jam/iv/syringe pump. Total fentanil adalah 900 ug iv. Pada akhir operasi nafas pasien spontan dan dapat diektubasi. Pasien dibawa ke ICU dengan manajemen nyeri pasca operasi menggunakan fentanil $500 \mathrm{ug} / 24 \mathrm{jam}$ iv 
dan ketorolak $30 \mathrm{mg} / 8$ jam iv ,dan dinilai ulang tingkat kesadaran di ICU dengan tingkat kesadaran GCS 15 .

\section{PEMBAHASAN}

Lundy pada tahun 1926, mengemukakan bahwa balans anestesi adalah keseimbangan antara agen anestesi dengan teknik anestesi untuk menghasilkan komponen anestesi yang berbeda yaitu analgesi, amnesia, relaksasi otot dan blok saraf otonom dengan pemeliharaan yang seimbang. ${ }^{1,2}$

Dapat diambil suatu kesimpulan bahwa penggunaan opioid pada balans anestesi adalah opioid sebagai salah satu komponen dalam balans anestesi yang dapat mengurangi nyeri pre-operatif dan kecemasan, mengurangi respons otonom dan somatik terhadap manipulasi jalan nafas, mempertahankan kestabilan hemodinamik selama rangsangan stimuli akibat pembedahan, mengurangi pemakaian anestesi inhalasi, dan sebagai analgesi segera pada pasca operasi. ${ }^{1,2,3}$

Opioid yang ideal untuk digunakan dalam balans anestesi selayaknya adalah menggunakan dosis titrasi yang disesuaikan, yang dapat mencegah respon nyeri dan rangsangan noksius akibat pembedahan, menumpulkan respon hemodinamik saat tindakan laringoskopi dan intubasi, hanya memerlukan sedikit penambahan obat anestesi yang lain (intravena atau inhalasi), tidak mendepresi fungsi kardiovaskular, memberikan ventilasi spontan yang adekuat secara tepat waktu, dan memberikan efek analgesia pasca operasi dengan minimal efek samping. ${ }^{1,2,4,5}$

Opioid dapat mengurangi nyeri pada ventilasi sentral karena merupakan agen yang efektif dalam mencegah hiperventilasi yang diinduksi oleh karena nyeri atau kecemasan. Akibat nyeri dapat meningkatkan tonus simpatis, yang mengakibatkan hipertensi, takikardi, peningkatan intrakranial (ICP) dan perubahan respon vasomotor. Mengontrol rasa nyeri dapat menstabilkan hemodinamik, mengurangi tekanan darah dan mengurangi rata-rata metabolik serebral terhadap konsumsi oksigen $\left(\mathrm{CMRO}_{2}\right)$, serta mengurangi ICP. Kurangnya rasa sakit yang memadai dapat juga menyebabkan disfungsi respirasi pasca operasi. Opioid dapat digunakan sebagai analgesi pasca operasi untuk mencegah disfungsi pernafasan dan dengan konsentrasi analgesi dapat mengurangi MAC anestesi inhalasi serta dapat mengurangi $\mathrm{CMRO}_{2}$ dan $\mathrm{CBF}{ }^{1,6,9}$

\section{Fentanil}

Fentanil merupakan opioid yang paling banyak digunakan dalam praktek anestesi saat ini karena opioid memiliki onset kerja cepat, durasi yang relatif singkat. Fentanil, yang disintesis pertama kali pada tahun 1960, memiliki beberapa keuntungan dalam penggunaannya, yaitu menghasilkan analgesia pasca operasi yang baik, mengurangi kebutuhan agen anestesi inhalasi yang berujung dengan 
mengurangi biaya dengan tujuan akhir ialah mempercepat pemulihan pasien. ${ }^{1,2,3}$

Pada saat induksi anestesi pemakaian fentanil sebagai loading dose dapat diberikan dengan dosis bekisar antara 2-6 $\mathrm{ug} / \mathrm{kg}$ yang dikombinasi dengan pemakaian agen hipnotik-sedatif yang lain seperti thiopental atau propofol dan pemberian relaksasi otot. Pemeliharaan anestesi dapat digunakan dengan $\mathrm{N}_{2} \mathrm{O}(60-70 \%)$ pada $\mathrm{O}_{2}$, menggunakan sedikit anestesi inhalasi. ${ }^{1,6}$

Penambahan fentanil adalah dengan dosis inkremental antara 25-50 ug iv yang dititrasi sampai mendapatkan efek yag diinginkan atau dengan dosis $0.5-2.5 \mathrm{ug} / \mathrm{kg}$ secara intermitten yang selama pembedahan dapat diulang dalam rentang waktu antara 15-30 menit ataupun dapat digunakan dengan infus secara konstan dengan dosis 0.5-5.0 ug/kgbb/jam) $)^{3,7,8}$

Dalam literatur, Barash Clinical Anesthesia, secara umum pemakaian fentanil dengan dosis bekisar antara 3-5 ug/ $\mathrm{kg} / \mathrm{jam}$ akan diperoleh masa pemulihan dengan ventilasi yang spontan pada akhir pembedahan. Pemakaian fentanil dikatakan dapat diberikan secara intermiten dengan loading dose fentanil adalah 5-10 ug/ $\mathrm{kg}$ atau dengan infus kontinu dengan rata-rata dosis $2-10 \mathrm{ug} / \mathrm{kg} / \mathrm{jam}{ }^{3,7,8}$

Bila fentanil akan diberikan sebagai dosis tunggal untuk anestesi, memerlukan dosis inisial yang cukup besar dengan range dose yang besar berkisar antara 50-150 ug/kgbb atau konsentrasi fentanil dalam plasma bekisar antara 20-30 ng/mL. ${ }^{1,7,8}$
Penggunaan fentanil dengan dosis bolus secara intravena dapat diberikan dengan dosis $3 \mathrm{ug} / \mathrm{kgbb}$ yang diberikan 25-30 menit sebelum insisi kulit, terbukti dapat mengurangi MAC pemakaian anestesi inhalasi kira-kira sebesar 50\% baik pada Isofluran maupun Desfluran. Pemberian fentanil dengan dosis $1.5 \mathrm{ug} / \mathrm{kgbb}$ yang diberikan 5 menit sebelum induksi dapat mengurangi pemakaian gas inhalasi baik Isofluran maupun Desfluran dalam $\mathrm{N}_{2} \mathrm{O}$ $60 \%$ dengan pengurangan hingga 60 $70 \%$. Konsentrasi plasma fentanil pada pasca operasi kira-kira $1.5 \mathrm{ng} / \mathrm{mL}$ tapi level sedikitnya mencapai $2-3 \mathrm{ng} / \mathrm{mL}$, biasanya diperlukan selama pembedahan bila agen inhalasi hanya $\mathrm{N}_{2} \mathrm{O}$. Pada pasca operasi, konsentrasi plasma fentanil bekisar antara 1.5-3.0 ng/mL dapat mengurangi respon $\mathrm{CO}_{2}$ sebesar $50 \%$. $^{1,6}$

Fentanil bersama dengan obat induksi anestesi seperti propofol dan thiopental dapat digunakan untuk menumpulkan respon hemodinamik selama tindakan laringoskopi dan intubasi trakea. Pemakaian dalam praktik secara klinis bisa digunakan secara titrasi pada dosis bekisar antara 1.5-5 u/kg sebelum pemakaian barbiturat atau obat induksi yang lain. Oleh karena kadar puncak fentanil dalam plasma antara 3-5 menit, maka sebaiknya titrasi fentanil diberikan secara komplit kira-kira 3 menit sebelum dilakukannya tindakan laringoskopi untuk mendapatkan hasil maksimal dalam usaha untuk menumpulkan respon hemodinamik terhadap tindakan intubasi trakea dan laringoskopi. $1,3,4,7,8$ 
Fentanil telah digunakan sebagai agen anestesi dengan range dosis yang besar. Penting untuk diketahui bahwa meskipun mula kerja fentanil cepat, tetapi membutuhkan waktu 5 menit untuk mencapai kadar puncak dalam plasma. Apabila fentanil diberikan dengan $\mathrm{N}_{2} \mathrm{O}$ dan oksigen saat induksi, dosis efektif untuk menghilangkan kesadaran ialah 8-23 ug/ kg. Perlu diingat bahwa kombinasi $\mathrm{N}_{2} \mathrm{O}$ dan opioid dosis sedang - dosis tinggi dapat menyebabkan kekakuan otot (muscle rigidity). Hal ini dapat dikurangi dengan memberikan berbagai ajuvan seperti benzodiazepin, barbiturat, dan pelumpuh otot. ${ }^{1,3,8}$

\section{SIMPULAN}

Opioid sebagai balanced anesthesia adalah pilihan yang baik pada kasus kraniotomi emergensi pada tumor meningioma, seperti halnya pada kasus ini. Dosis opioid dengan titrasi diperlukan untuk menumpulkan respon hemodinamik selama laringoskopi, intubasi trakea, dan beragam rangsangan bedah dan telah terbukti tidak meningkatkan metabolik serebral dan intrakranial. Dosis opioid dengan titrasi memiliki efek yang diinginkan selama pembedahan dan penyembuhan yang baik segera pasca operasi. ${ }^{2,3}$

Fentanil merupakan pilihan yang baik sebagai bagian dari balanced anesthesia terbukti menghasilkan masa pemulihan yang cepat dan sebagai analgesi pasca operasi yang memberikan hasil akhir yang memuaskan, hal ini terbukti dengan derajat kesadaran pasien yang makin meningkat.

Tabel 1.Rentang Kadar Konsentrasi Plasma Opioid (dalam ng/mL) ${ }^{10}$

\begin{tabular}{ccccc}
\hline & Fentanil & Sufentanil & Alfentanil & Remifentanil \\
\hline Predominan agen & $15-30$ & $5-10$ & $400-800$ & - \\
\hline Bedah Mayor & $4-10$ & $1-3$ & $200-400$ & $1-3$ \\
\hline Bedah Minor & $3-6$ & $0,25-1$ & $50-200$ & $0,3-0,6$ \\
\hline Ventilasi Spontan & $1-3$ & $<0,4$ & $<200$ & $0,2-0,4$ \\
\hline Analgesia & $1-2$ & $0,2-0,4$ & $50-150$ & \\
\hline
\end{tabular}




\section{DAFTAR PUSTAKA}

1. Barash, Paul G.; Cullen, Bruce F.; Stoelting, Robert K. Opioid. In :Clinical Anesthesia, 5th Edition Lippincott Williams \& Wilkins. 2006.353-400.

2. Andrews DT, Leslie K, Sessler DI, Bjorksten AR: The arterial blood propofol concentration preventing movement in $50 \%$ of healthy women after skin incision. Anesth Analg 1997; 85:414419.

3. Fukuda K. Intravenous opioid anesthetics In : Miller's anesthesia. 6th ed. Churchill Livingstone, Philadelphia, 2009: 379-424

4. 4. Smith C, McEwan AI, Jhaveri R, et al: The interaction of fentanil on the $\mathrm{Cp} 50$ of propofol for loss of consciousness and s $\mathrm{k}$ i n incision. Anesthesiology 1994; 81:820828.

5. Jaeckle KA, Digre KB, Jones CR. Central Neurogenic Hyperventilation: Pharmacologic intervention with morphine sulfate and correlative analysis of respiratory, sleep, and ocular motor dysfunction. Neurology 1990; 40 : 17151720.

6. Katoh T, Uchiyama T,Ikeda K : Effect of fentanyl on awakening concentration of sevoflurane. Br J Anaesth 1994; 73: 322325.1

7. Glass PSA, Jacoba JR,Smith LR et al : Pharmacokinetic model-driven infusion of fentanyl : Assesment of accuracy. Anesthesiology $73: 1082,1990$.

8. Morgan GE et al : Non Volatile Anaesthetic Agents. In : Clinical Anesthesiology . 4th ed. Lange Medical Books/ Mc Graw Hill. 192-196, 2006.

9. Cottrell et al : The Management of Pain in the Neurosurgical Patient. In : Handbook of Neuroanesthesia .5th ed. Lippincott Williams \& Wilkins. 2012.7076.

10. Bailey PL. Egan TD, Stanley TH. Intravenous Opioid Anesthetics. In: Miller RD (ed). Anesthesia, 5th ed. New York, Churchill Livingstone,2000,p 335 